\title{
Acting Oneself as Another: An Actor's Empathy for her Character
}

\author{
Shaun Gallagher ${ }^{1,2}$ [D Julia Gallagher ${ }^{3}$
}

Published online: 12 January 2019

(c) The Author(s) 2019

\begin{abstract}
What does it mean for an actor to empathize with the character she is playing? We review different theories of empathy and of acting. We then consider the notion of "twofoldness" (Wollheim), which has been used to characterize the observer or audience perspective on the relation between actor and character (Smith). This same kind of twofoldness or double attunement applies from the perspective of the actor herself who must, at certain points of preparation, distinguish between the character portrayed and her own portrayal effected in her craft. We argue that this concept helps us to understand how the actor can empathize with her character. For the actor who must study and rehearse her character, empathy may begin with higher-order (narrative or imaginative) processes that provide a contextualized understanding of the character. This understanding eventually integrates with more basic empathic processes in her actual performance.
\end{abstract}

Keywords Acting $\cdot$ Empathy $\cdot$ Character $\cdot$ Imagination $\cdot$ Narrative $\cdot$ Twofoldness

"An actor's job is empathy." (Natalie Portman) ${ }^{1}$

"[T]o play truly means to be right, logical, coherent, to think, strive, feel, and act in unison with your role.... and thus assimilate a psychological technique of living a part" (Stanislavski 1936, p. 15, 16).

In this paper we address the following question: what does it mean for an actor to empathize with the character she is playing? The answer lies somewhere at the intersection between theories of empathy, of which there are many, and a variety of acting practices, of which there are many. This is a complex landscape. Our first task is to map this landscape (Sects. 1, 2, 3) and then to define our position on that map (Sect. 4).

Shaun Gallagher

s.gallagher@memphis.edu

1 Department of Philosophy, University of Memphis, 337 Clement Hall, Memphis, TN 38152, USA

2 Faculty of Law, Humanities and the Arts, University of Wollongong, Wollongong, Australia

3 West Hollywood, Los Angeles, USA

\section{Setting the Stage: Debates About Empathy}

The psychologist Edward Titchener (1909) translated the German term Einfühlung by the new English term 'empathy' just around the time there was a lively debate in Germany about Einfühlung. Theodor Lipps (1906, 1909), a major figure in this debate, employed the term to refer to both our experience of aesthetic objects and our sense of other minds. Whereas Lipps thought of empathy as an everyday occurrence involving an automatic embodied resonance, Wilhelm Dilthey conceived of it as a methodological tool to be used for historical analysis and more generally as a method for the human and social sciences (see Stueber 2006, pp. 11-12). Dilthey (1992) contended that empathy involved a "transposing" [Hineinversetzen] process, where one puts oneself into the position of the other person. We want to immediately note the direct relevance of these considerations to acting: that there is an aesthetic object in the form of a character to portray; that empathy might count not only as something that happens, but as a method; and that it involves putting oneself into the other's perspective or situation. To make these relevant points clear, and to set the stage for our discussion, we think it is important to set out some of the details of the debate about empathy.

According to Moritz Geiger (1910), who provided a succinct summary of the early twentieth-century debate,

$\overline{1}$ Quoted at http://entertainment.inquirer.net/68811/an-actors-job-isempathy. 
some theorists considered empathy to be a form of imagination, while others thought of it as a real instantiation of another person's emotion. Lipps embraced the latter view. He claimed that we experience (not just imagine) the same thing the other person experiences. Thus, if we experience the anger of the other person, "this anger is not something that is simply objectively there facing us, but we are in it. We live in this anger, it fully gives itself, although for other reasons it does not have the same effectiveness as anger in daily life" (Geiger 1910, pp. 22; trans. revised). ${ }^{2}$ How we do this involves a form of projection in which we add something of ourselves to our experience of the other's external signs (gestures, facial expressions, etc.): "we add something mental from our own inwardness-here we have a special act of the spontaneity of a mental nature, and not a simple intake of the data transmitted to us from the outside" (Geiger 1910, p. 24, trans. revised; see; Lipps 1905, p. 17). Projection involves an elicitation of our own experience to fill in what we cannot access of the other's experience.

Although Dilthey thought of empathy in similar terms of transposition and projection, he distinguished between "elementary understanding" and higher forms of understanding, both of which involve empathy. Elementary understanding arises in the context of practical life and our communicative practices. It involves the interpretation of basic expressive behaviors or activities ("such as picking up an object, letting a hammer drop, cutting wood with a saw"), which in turn add up to complex actions. To understand such actions one relies on one's own experience and the "projection of the self into some given expression" (Dilthey 1976, p. 226).

The higher form of empathy is based on this elementary transposition (Dilthey 2002, p. 235), but with added concerns about context or the connectedness of experience, which "requires that the understanding go forward with the line of the events themselves. It must advance continually with the course of life itself. The process of transposing oneself or transposition expands to make re-experiencing a creation along the line of the events" (Dilthey 2002, p. 235). This fuller or higher sense of empathy, he contends, is facilitated by artistic expression in poetry or theater, or by fictional or historical narrative. It involves a process of an imaginative re-presentation (Vergegenwärtigung) of a particular situation which "stimulates a re-experiencing in us" (ibid, 236). Specifically, by transposing oneself into the other's circumstances one can re-live the other's feelings. "Thus human beings who are determined from within can experience many other kinds of existence through their imagination. Confined by circumstances, they can nevertheless glimpse

\footnotetext{
2 Similar claims can be found in eighteenth-century French authors such as Bernard Lamy (1699) and Jean-Baptiste Du Bos (1748). See Foster (2005).
}

exotic beauties of the world and regions of life beyond their reach" (ibid, 327). This advanced form of empathy requires that we make judgments about the other person's character and capacities. Context and circumstances matter in order to gain insight.

A number of phenomenologists (Edmund Husserl, Edith Stein, and Max Scheler, for example) joined the debate by offering a perceptual account of elementary empathy. In contrast to Lipps, for whom we come to experience the same emotion that the other experiences, according to Husserl, when we grasp that another person is angry, we do not necessarily feel anger ourselves; if we see that someone else is fearful, we do not empathize by experiencing fear ourselves (Husserl 1973, p. 188). Zahavi (2014, p. 113) clarifies this objection: "How plausible is it to claim that I have to be scared myself in order to understand that my child is scared, or that I need to become furious myself if I am to recognize the fury in the face of my assailant."

The phenomenologists see a second problem with Lipps' position. It's not clear that we project (or why we are warranted to project) our own experience onto the other. At best, according to Stein (2012), this kind of projection would explain a form of automatic mimicry/contagion, which falls short of empathy. More positively, according to the phenomenologists, empathy involves becoming perceptually aware of the other's intentions and affective states. For both Husserl and Stein empathy is a unique form of perceptual intentionality directed at the other as an embodied subject. In empathic perception we perceive the other's body not as an objective entity (Körper), as a scientist might perceive it, but as an experiencing or lived body (Leib), a body that is expressive of the other's subjectivity. I get to this sense of the other's body through the ambiguous experience of my own body as both lived and objective. ${ }^{3}$ Rather than a case of attributing, imagining, projecting, inferring, or cognizing the mental states of others, empathy involves a complex perceiving or apperception of the other's intentions and feelings that are perceptually present in her gestures and expressions (Stein 2012, p. 3; Husserl 1952, p. 235). The phenomenological notion of pairing (Paarung) (Husserl 1964), on which empathy is based, is a perceiving of the other's embodied behavior in terms of a set of pragmatic and expressive capabilities that are also possibilities for my own embodied existence. Accordingly I see her bodily behaviors as intentions or feelings; in other words, I don't perceive her in isolation but rather as directed at our shared world.

\footnotetext{
${ }^{3}$ Zahavi (2001, p. 161) explains that, according to Husserl, it "is exactly the unique subject-object status of [my own] body, the remarkable interplay between ipseity and alterity characterizing body-awareness that provides me with the means of recognizing other embodied subjects [as lived bodies]".
} 
If we fast-forward 100 years we find a renewed debate on the concept of empathy underway at the beginning of the twenty-first century. This debate repeats many of the terms of the earlier one, including a distinction between elementary and higher-order empathy, and contrasting views similar to those defended by Lipps and the phenomenologists concerning elementary empathy, although now in the light of recent advances in the neurosciences. Indeed, the more recent debate has been motivated in part by the neuroscience of mirror neurons (MNs), the activation of which has been interpreted as a form of simulation in philosophical and psychological accounts of social cognition. Simulation is a complex concept, but on one view simulation involves imaginatively placing ourselves in the shoes of the other person and asking what we would do in her situation. This kind of simulation is considered a form of empathy, where "the term 'empathize' [is] roughly equivalent to 'simulate' (in an inter-subjective fashion)" (Goldman 2006, p. 17, 205, 291; 2011, p. 34).

Goldman (2006) and Stueber (2006), along with neuroscientists like Gallese (2001), argue that a very basic kind of automatic empathic simulation, which Gallese calls embodied simulation, is linked to the activity of the MN system. In this respect, simulation theory draws on Lipp's account of empathy as an automatic imitation or resonance which allows us to experience (not just imagine) the same thing that the other person experiences. MNs are activated when an agent engages in intentional action, and also when the agent observes another agent engaging in intentional action. Accordingly, MNs are said to simulate or match the other's actions, intentions and/or feelings by activating the same mechanisms responsible for one's own action and first-person agentive-experience. On this view, the automatic simulation or matching just is a basic form of empathy.

Again, as in the earlier debate, phenomenologists take issue with the claim that empathy reduces to an automatic activation of the motor system, something that seems closer to contagion than to empathy (Zahavi 2012). Or again, it is not necessary to match or replicate anger in my system, for example, in order to grasp the fact that the other person is angry (Zahavi 2014). I can never fully inhabit the other's feeling from a first-person perspective. But I can attune to others' intentions and emotions on the basis of what I perceive of their behaviors and bodily expressions (Moran 2017), which, at least in part, constitute their intentions and emotions. To the extent that I understand their intentions and emotions in this way, that just is what phenomenologists call empathy.

\section{Spotlighting Imagination and Narrative}

In this and the following sections we set out a contrast between a simulation theory of empathy and an enactive theory of empathy, and we present arguments in favor of the latter. In the debates rehearsed above the focus was on the question: to what extent does empathy require (or not require) that one enters into the other's perspective or situation in processes that involve automatic resonance or simulation, imagination, projection, or simply perception? To get us closer to the question of the actor's empathy for her character, however, we want to return to Dilthey's distinction between elementary versus higher-order empathic understanding, and the idea that we may be able to use empathy as a method. Dilthey's distinction is mirrored in the contemporary distinction between basic and higher-order simulation (Goldman 2006; Stueber 2006). Basic empathy, associated with MN activation, as Stueber suggests, is not sufficient to "explain and predict a person's behavior in complex social situations" or to provide "a full grasp of all mental concepts that we attribute to the typical adult" (2006, p. 147). We require something more for these abilities, namely, a higher-order empathy. According to a number of simulation theorists, this more sophisticated form of understanding requires the use of imagination and an understanding of the other's contextualized situation (Goldman 2006; Stueber 2006). On a simulationist view, for example, the empathic state involves an "as if" or vicarious affective state, generated by the empathizer's imaginative portrayal of another person's affective state. This capacity for creating vicarious experiences is based on a specific kind of imagination (call this S-imagination), ${ }^{4}$ which involves the running of off-line, high-level (i.e., explicit, conscious) simulations of the other person's mental states (Vignemont and Jacob 2012, 2011).

There are several problems with the simulationist account (see Gallagher 2007, 2008, 2012). We'll mention just two here: the starting problem and the diversity problem. The starting problem concerns how one can initiate this sort of S-imagination. This problem is apparent in Goldman's description of the first step. "First, the attributor creates in herself pretend states intended to match those of the target [the other person]. In other words, the attributor attempts to put herself in the target's "mental shoes"' (Goldman 2005, pp. 80-81). This first step already seems to assume that we understand the other person, i.e., that we know what mental states to imagine. Yet that is what simulation is meant to explain. How do I know what belief or desire matches the

\footnotetext{
${ }^{4}$ Goldman (2006) calls this type of imagination 'enactive' or E-imagination. To avoid some confusion with relevant enactivist approaches to empathy (discussed below) we'll call this type of imagination S-imagination (for simulative imagination).
} 
other person's mental state? If I already know what state matches the target, then the problem of understanding or empathizing with others, as defined by simulation theory, would already be solved. The diversity problem is related to an objection raised by Ryle (1949) and a number of phenomenologists, namely that if we limit ourselves to our own first-person experience, or to what we can imagine based on our own experiences, and project that onto the other person, it's not clear that we are able to escape our own narrow perspective or genuinely grasp the other's mental states, which may be quite different from our own. S-imagination is based on $m y$ first-person experience where I ask what $I$ would do in that situation (Gazzola and Keysers 2008). It's not clear that knowing what I would do gives me insight into what anyone else might do. There is a large diversity of experiences that others can have; but S-imagination seems designed simply to project our own experience onto the other.

A contrasting, non-simulationist theory of higher-order empathy, and one that we prefer, argues that I can start to imagine the other person's situation (rather than her mental state), and thereby start to empathize with her, by drawing on a rich store of narratives derived from both personal and cultural sources (Gallagher 2012; Gallagher and Hutto 2008; Hutto 2007). On this narrative-practice view, our reliance on narrative reduces the need for simulationist style imagination. Since empathy is other-directed in a strong sense, it is not sufficient for empathy to simply view the other through the lens of my own experience. Rather, through narrative practices I gain an openness to understanding another's life story, and to understanding his experience in his context. This kind of N[arrative]-imagination, by drawing from a diversity of narratives that have informed my understanding and enriched my imagination, does not depend on simulation, conceived of as relying only on my own narrow experience. In contrast to Stueber (2008), who suggests that narrative simply provides "hints and clues" to enhance the simulation (empathetic reenactment) process, the narrative view is that we rely heavily on narrative resources, which open up the process to the more diverse circumstances that may characterize the other. Narrative resources can include our own self-narratives, but importantly includes the diverse narratives of others and more general cultural narratives (novels, plays, films, etc.) with which we are familiarized starting at a very young age.

$\mathrm{N}$-imagination also starts at a very young age. We appeal here not only to accounts of the development of narrative competency in early childhood, but also to accounts of imagination as an enactive practice (Rucinska 2014). ${ }^{5}$

\footnotetext{
5 “Children's first narrative productions occur in action, in episodes of symbolic play by groups of peers, accompanied by-rather than solely though-language. Play is an important developmental source of narrative" (Nelson 2003, p. 28). As Richner and Nicolopoulou (2001, p. 408) put it, there are "two aspects of children's narrative
}

For example, Ryle's account of imagination suggests that imagination starts in childhood, not as a set of psychical processes in the head, but as a form of pretending or playacting. Ryle's example is the child pretending to be a bear. In this case the child "roars, he pads around the floor, he gnashes his teeth, and he pretends to sleep in what he pretends is a cave" $(1949$, p. 243$)$. That is, the child does not first draw up some image in his head, and then proceed to playact it out; rather, as Ryle suggests, the imagining is in the performance of playacting. This kind of playacting is a case of (en)acting oneself as another, and it follows a narrative structure. ${ }^{6}$

This non-simulationist account of narrative practices is part of an enactive theory of higher-order empathy. Empathy of this sort depends on the exercise of $\mathrm{N}$-imagination, which in some cases can be embodied in one's actions, as in the case of the child's pretend play. The enactive account of empathy also includes an alternative interpretation of the role of MN activation in basic empathy. The enactive theory follows the phenomenological idea that basic empathy is perceptual, and specifically that it involves an action-oriented or enactive perception. I perceive the world in terms of how I can engage with it; and I perceive others in terms of how I can interact with them, even if I am not intending to interact with them. Within this perceptual process MNs are activated not for a simulative matching of the other's just past action that I have just perceived, but as an enactive preparation for responding to the other. Basic empathy involves this other-oriented response. Responding to the other includes the possibility of imitating them, but, as we'll see below, it also includes the possibility of acting oneself as another, which is not reducible to imitation.

Dilthey's suggestion that we can use empathy as a method for gaining an understanding of others seems to apply to higher-order empathy rather than to processes of basic empathy. We note, however, that these two forms of empathy may be causally and reciprocally related. It is intuitive to think, as Dilthey did, that higher-order empathy may depend in some way on basic empathy, so that a purely intellectual understanding of a person's context may not elicit a higher-order empathy unless some form of basic empathy is activated. It is also the case, however, that understanding the other's context or story can modulate or even generate more basic resonance processes, as sometimes happens in

Footnote 5 (continued)

activity which are too often treated in mutual isolation: the discursive exposition of narratives in storytelling and their enactments in pretend play."

${ }^{6}$ One finds a similar idea in body-psychotherapy where patients are asked to act out their stories. For more on the relation between imagination, narrative, and pretend play, see Gallagher 2017; Gallagher and Hutto 2019 


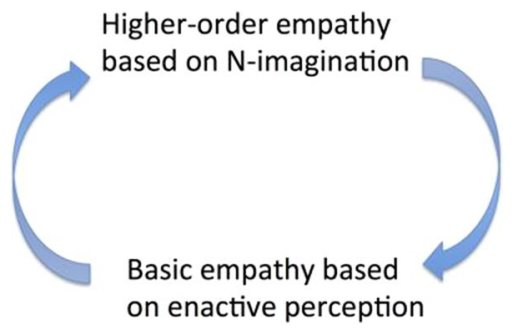

Fig. 1 An enactive model of empathy

reading a novel or viewing a film. Empirical studies show, for example, differential mirror-system responses to the (fictional) punishment of someone who the subject knows has either cheated or played fairly at a game show-specifically, no or less response to the punishment of the cheater (Singer et al. 2006). Other studies show that we are more inclined to act on our empathic feelings, and act altruistically, when we know the other person's personal narrative in contrast to knowing impersonal information about a general situation (Slovic 2007). Specific types of social knowledge, or knowing the context or the other's story, then, may have an effect on basic empathic processes, making them less than automatic. Such reciprocal causal relations suggest that basic empathy and higher-order empathy are integrated processes and are thus not always clearly distinguishable. We can represent this relation in the following (Fig. 1).

The distinction between higher-order, $\mathrm{N}$-imaginationbased empathy and basic empathy is similar to what Kurt Goldstein called categorical or abstract versus concrete attitudes. In this respect, we should think of the relation between basic empathic processes and higher-order empathy more in terms of a gestalt relation as Goldstein suggests.

[The concrete attitude] is embedded in and codetermined by the abstract attitude. For instance, in the normal person both attitudes are always present in a definite figure-ground relation. (Goldstein and Scheerer 1964, p. 8)

\section{Acting and Acting Method}

It is the crudest form of empathy when the actor simply asks: what should I be like if this or that were to happen to me? (Brecht 1975a, p. 195).

Our question is whether an actor can or does empathize with the character that she plays. If so, precisely what form does this empathy take? One possibility is that over the course of studying a role, an actor moves through different stages that involve both (or some integrated process of) basic empathy and higher-order empathy. Indeed, one might think that this is the ordinary course of events more generally in contexts that involve empathizing with others. That is, we may start in an initial encounter with either a basic form of empathy transitioning into a higher-order form as one comes to know the other's (or the character's) story and circumstances, or vice versa. One challenge for this view with respect to acting is that, in most circumstances, the character to be (en)acted (especially if the character is fictional) is not physically present. One might start with a script that describes the character, or, in the case of a character who is a historical figure, reading material or a documentary film. These are different situations, but in either case there is no other person present in-person or face-to-face. Do such situations elicit anything like an immediate form of basic empathy?

In the case of starting with a script, we are not perceiving another person, or seeing someone engaged in intentional actions. This eliminates the phenomenological idea of a direct perception of the other's experience in their gestures, facial expressions, etc. But there is some evidence that reading about actions activates our motor system, and that, in so doing, reading generates a type of simulation or resonance (Hauk et al. 2004; Tettamanti et al. 2005). The silent reading of action words (e.g., lick, pick, kick) leads to activation of different areas of the premotor or motor areas involved in the control of mouth, hand, or foot, respectively. This may suggest a very basic motor resonance of the sort that Lipps describes in terms of proprioceptive-kinaesthetic activations/experiences. Even if the mirror neuron system is activated by reading specific words (as Gallese [2008] tentatively suggests), however, this seems a poor cousin to basic empathy for the person we read about, even if the text or script is action packed. Albeit specific for action components (kicking vs. licking), it seems more like a typical arousal response that happens for a variety of objects. The sight of a hammer, for example, will activate canonical neurons in the premotor cortex suggesting that we see things in terms of the action possibilities they afford. If something similar happens when we read a sentence such as 'He picks up the hammer', it is not clear that this is empathy for the character, rather than the arousal of an instrumental attitude in relation to the hammer.

We know, however, that reading a text or watching a film can elicit more specific intersubjective responses-various emotions, empathy, and sympathy. "Film experience is embodied: the brain and the body-even viscera and the skin-constantly resonate in accordance with the film's flow, with changes in muscular tension, perspiration, stomach state, etc." (Grodal and Kramer 2010; see; Raz et al. 2012). This may be "guided by the narrative and aesthetic orchestration of a film" (Grodal and Kramer 2010, p. 28). That MN activations, or processes involved in direct intersubjective perception, are possible when watching films has been suggested by Gallese and his research group in Berlin. 
On this view, we can empathize with a character in a film by simulating her actions and emotions. This is evidenced by physiological changes such as galvanic skin response (GSR), which indicates emotional arousal (see Kaltwasser 2018). Murray Smith (2017) picks up on this account and on Gallese's notion of embodied simulation, as a way to explain a viewer's empathy with a character. "Mimicry of basic actions and emotions may scaffold the imagination, including the empathic imagination, of more elaborate, finely specified states of mind" (Smith 2017, p. 180). These studies suggest that an actor, in reading a script or in viewing a documentary film about the character, could get an initial empathic feel for her character. This seemingly approaches the immediate aspects of basic empathy, although this empathic response may not be exactly the same, or as strong as when one encounters someone in person.

The authors just cited interpret such resonance or MN activation in terms of simulation, but, as suggested above, we can also interpret these processes from an enactivist perspective. Two things should be kept in mind. First, basic empathy seems more complicated than simply the matching or mimicking of what one sees. In reading a novel or watching a film the context provided by the novel or film matters. In this respect, reading and perceptual processes are already primed by and integrated with complex imaginative processes which can easily include an action-oriented stance concerning what I would do or be prepared to do in response to the character I was viewing or about whom I was reading. ${ }^{7}$ This is the enactive interpretation of such processes, which acknowledges some action-oriented complexity. Second, the discussion focuses on a reader or viewer as part of the audience. Whether the simulationist description applies to the audience member or not (and this could include an actor who is in the process of studying in order to understand the character), it doesn't apply to the actor who is engaged in a performance. In the latter case, as Cook (2007, p. 591) points out, an actor does not imitate a character: "actors perform actions required of their characters-they do not 'imitate' this action, they perform it."

If the processes just described involve basic empathy, they also already seem to involve higher-order empathy and the use of imagination and narrative. As indicated by Grodal

\footnotetext{
7 There is much more to be said about this than we can discuss here. The idea that perception (and reading) and imagination are closely intertwined is a theme that can be found in the phenomenologists (e.g., Husserl 1980; Sartre 2004), in much of the cognitive science literature just cited, which suggests that imagination activates early sensory areas in the brain (see Kosslyn and Thompson 2003) and in recent predictive processing models that contend that perception and cognitive processes like reading are informed by priors (e.g., Price and Devlin 2011). These different literatures, however, make dramatically different assumptions and it would take more room than we have here to adjudicate among them (see Gallagher and Allen 2018).
}

and Kramer (2010, p. 28), these processes are already guided by the narrative of the film or novel. From the perspective of professional practice, pursuing these narratives is part of the preparatory work that the actor must do. Especially at the beginning of the process, in many cases one needs to engage in imaginative practices in order to non-judgmentally attune to the character. Here we distinguish between an empathic understanding of the character, and an evaluative judgment about the character. An evaluative judgment can rob an actor of empathy, creating too much distance or separation between the actor and the character. Indeed, there may be some evaluative components involved in the perceptual processes of basic empathy, ${ }^{8}$ and one may require some methodological exercises to overcome such effects. Instead of making an evaluative judgment about the character, actors will sometimes use higher-order empathy as a method, explicitly setting aside any evaluative judgments, potentially to seek out and accept that this character is the way she is because of specific circumstances. Here one possible aim would be to empathize with the character through an understanding of those circumstances. In some cases this may involve creating the character as one goes through a systematic absorption of the material, explicitly aiming for an empathic understanding in a process of integrating each word/action of the character into one's own performance (Goldstein and Winner 2010). This would be one way to use a higher-order empathy as a method in order to achieve something like a basic empathy for the character.

This use of a higher-order form of empathy, then, may involve an actor's research about her character with the aim of understanding the detailed contexts or circumstances of a character's life or story. In this way the actor may use her $\mathrm{N}$-imagination to enact a sense of the physical, mental, emotional feel of what a character would go through in a certain situation. An actor doesn't need to get physically beaten to know what it physically, mentally, and emotionally feels like to be in a physically abusive relationship, for example. This type of process, however, is not reducible to the immediate resonance of basic empathy-it requires a more mediated use of $\mathrm{N}$-imagination, drawing not only on one's personal experience, but also on more general narrative resources. This correlates to an actor's work of getting to know her character.

As we noted, at the beginning of an acting process the actor may be in a similar observational position as someone in an audience (reading a narrative or seeing a film about the character). The "work" of the actor in this case is to

\footnotetext{
${ }^{8}$ Studies that show that activation of early visual areas are not evaluative (or reward) neutral (Shuler and Bear 2006), or neutral with respect to perceiving a character as belonging to an in-group versus out-group (e.g., Xu et al. 2009).
} 
transition from an observer-audience stance to a position of enacting the character, which is not just representing a character as a painting might represent an idea, but a form of living or performing her character. In some cases, this work may be harder than in other cases. Consider, for example, a view (albeit a simulationist view) of what happens when, as part of the audience, one views a character in a film:

Engagement is fed by the viewer's own previous experiences of pain and loss, which can influence the 'like me' framework-depending on the relationship between viewer and character. Sometimes a character will not invite the vicarious sharing of emotions. The character's actions or the situation they are in could be too farfetched for the viewer to allow empathy; in the latter case conscious simulation by the viewer might be required in order to understand the character. (Grodal and Kramer 2010, p. 27, citing; Smith 1995).

From the perspective of the actor, however, if a character does not invite the vicarious sharing of emotions, that makes the work of empathy more difficult, but even more important. In some circumstances it may be right to think that the actor fails if they cannot empathically get inside the character's "farfetched" actions (but we'll see below that this is not universally accepted in acting theory).

One might also think that by means of this higher-order empathic process of getting inside the character's "head" or getting familiar with his actions in various situations, one's more immediate feel for the character might be strengthened. In this way, higher-order empathy does not remain purely an intellectual understanding; it may be closer to an emotional understanding, as it is described by actors. One way to understand this is that the higher-order work of empathy (using narrative-imaginative practices) leads to a performance that elicits, in the actor, something closer to basic empathy-in-performance, allowing the character to come alive in the actor's work.

Whether this feeling approaches an actor's identity with the character, or a strong form of attunement, is an issue that may qualify what can be described as empathy. On the one hand, most theorists of empathy maintain that empathy is not equivalent to an identity with the other person; empathy requires that the distinction between self and other is maintained (Decety 2005). Paul Ricoeur (1992, p. 193) calls this a 'nonsubstitutibility' anchored in the use of the first-person pronoun. On the other hand, one might think that when the actor is finished with her research and is actually performing her role, she is bringing the character to life, and her motor system is enacting the character in a way that goes beyond empathy. ${ }^{9}$ She is no longer empathically observing

\footnotetext{
${ }^{9}$ Let's note that this is complicated further by the fact that in performance an actor is typically working with others-other actors and the director, for example — and even if the actor is alone on theatrical
}

or simulating the actions of another; she is enacting them, and the actor/character is saying ' $I$ ', so that the distinction between self and other diminishes.

These are issues that are often discussed in acting theory. Here we briefly discuss three different theories to see how they approach questions about empathy. These are three out of many methods of acting, although these are classic and well-known theories-pillars on which others have built.

(1) One view, which derives from Denis Diderot (1883), is that the actor must remain "cold" and avoid empathy for her character. This was also the position of Bertolt Brecht. Brecht takes empathy to mean matching emotional states, as one finds in simulation theory. The actor must try to avoid empathically matching a character's emotional state by practicing an "alienation effect," which "intervenes, not in the form of absence of emotion, but in the form of emotions which need not correspond to those of the character portrayed" (Brecht 1975a, p. 94). The actor should avoid being infected with the emotions portrayed; if emotions are to be portrayed, it is not by means of empathy (Brecht 1975b, p. 145).

John Metcalf describes a method that would guide the actor to this end. The actor must maintain a double consciousness- "one part of it being devoted to the character portrayed, the other part maintaining a watchful and critical attitude on the part of the actor's own real self" (Metcalf 1931, p. 236). Imagination, according to Metcalf, makes this possible by allowing the actor to remain somewhat distant from a real emotion, which may be a form of protection for the actor. "If the actor cannot vividly represent to himself in imagination the mental attitude of the character he is to portray, it is hopeless for him to try to represent it to other people. Imagining a given mental state tends to stimulate the motor responses appropriate to that state, and these, once produced, are controlled, modified, selected, and

\section{Footnote 9 (continued)}

stage or in soliloquy, there is also an audience that responds to the character. All of these others may generate their own intersubjective responses that can modulate an actor's performance and her empathy for her character. As Grodal and Kramer (2010, p. 27), note: "The director's lack of craftsmanship might also fail to encourage empathetic resonance, despite their intentions." An audience's empathic or non-empathic response may interfere much less with the actor's empathic resonance with her character if the actor is fully engaged with her performance. We don't try to answer this question herewhether it is possible or not to ignore audience reaction. One might argue that if an actor is swayed in empathic resonance by an audience's reaction, then some form of evaluative judgment may be interfering with her performance, and with her empathy for the character in general. 
developed through rehearsal in the interest of the art of the theatre" (p. 236). Metcalf follows Titchener in distinguishing the imagined/virtual kinaesthetic response from a real one, where the kinaesthetic image is limited in terms of what motor processes are activated. "Real emotions are out of place on the stage" (p. 237).

(2) In contrast, Konstantin Stanislavski advises the actor to draw on her own experience. He thus builds a simulationist view that encourages empathy.

Once you have established this contact between your life and your part, you will find that inner push or stimulus. Add a whole series of contingencies based on your own experience in life, and you will see how easy it will be for you sincerely to believe in the possibility of what you are called upon to do on the stage... The feelings aroused will express themselves in the acts of this imaginary person had he been placed in the circumstances made by the play. (Stanislavski 1936, p. $41,49)$

The actor's job, according to Stanislavski is to create the inner life of the character and to express it in artistic form. This is an embodied craft, allowing for controlled responses of vocal and physical apparatus (Stanislavski 1936, pp. 15-17). ${ }^{10}$ According to Jean Benedetti (1998, p. 2), Stanislavski requires the actor to draw on personal experience in portraying a character.

Since there is no 'character' out there somewhere, only me on the stage in an imaginary situation, my initial exploration of the play must be as myself, as $m e$. To turn fiction into fact for me, I have to ask myself at every point in the play, 'If this situation were true, what would I do?' (Benedetti 1998, p. $8)$.

The actor needs to draw on her own affective memory so that the fictional character can express real emotion-precisely the thing that Metcalf suggests has no place on the stage. This is accomplished through a form of empathy that seemingly involves both a simulation based on the actor's own experience, and a higher-order use of narrative as the actor (and his company) explores the play to gain "a sense of the play as a whole, and its meaning"-its complete narrative context (Benedetti 1998, p. 6).

This approach is also consistent with an idea prevalent in Dilthey's romantic hermeneutics, namely that

\footnotetext{
10 See Connolly and Ralley (2007) for an analysis of Stanislavski from the perspective of embodied cognition, action-orientation, and MNs. Also, Hatfield et al. (2011) for the importance of action/posture, etc. in Stanislavski's method. Cook (2007, p. 592) provides interesting examples of how acting can affect both body image and body schema.
}

we are able to empathically understand the other, even someone historically or culturally removed from us, because there is something like a universal human nature that we can tap into. Dilthey follows Schleiermacher in appealing to empathy as a shared form of access that is universally human. This was the basis for Schleiermacher's "divinatory" method of interpretation. "The divinatory is based on the assumption that each person is not only a unique individual in his own right, but that he has a receptivity to the uniqueness of every other person" (Schleiermacher 1977, sect. 2.6). On this view, unique or not, we are all capable of the same or similar things. Empathy allows the actor to see a character as if it were she (the actor) faced with the different circumstances that characterize the character's life. An actor can accept the circumstances as her own because they can and always will be a possibility for her.

(3) Sanford Meisner's approach can be conceived as a move away from the simulationist view toward a more enactivist or action-oriented method. Meisner recommends that the actor "gets out of [her] head," i.e., shifts away from her own affective memory, or internal thoughts about, or higher-order imaginative simulations of the character, which have a "tendency to make actors more introverted.... Introverted actors tend to retreat into their thoughts, where they can't react fully to what goes on around them." (Esper and DiMarco 2008, p. 215). The actor, to perform the character's actions, to become the character, should engage instinctively and emotionally with the present environment and the other actors.

Getting out of one's head is an enactivist conception that takes as a starting point the fact that we are dynamically in a world of affordances. In this regard, Lutterbie (2011, p. 102) cites Evan Thompson's enactivist view of empathy: "This dialogical dynamic is not a linear or additive combination of two preexisting, skull-bound minds. It emerges from and reciprocally shapes the nonlinear coupling of oneself to another in perception and action, emotion and imagination, gesture and speech." Although Lutterbie mentions imagination, the emphasis here is on basic empathy. Acting, especially acting face-to-face with other characters, draws on one's natural interactional processes and on the affordances provided by one's surroundings. A performance that follows such principles just is an empathic performance since, as Thompson suggests, such concrete encounters "of self and other fundamentally involve empathy, understood as a unique and irreducible kind of intentionality" (Thompson 2001, p. 1). In this regard, the enactivist account follows the phenomenological conception of empathy as a "non-inferential bodily [and 
perceptually-based] pairing of self and other" (2001, $p$, 9) which takes place, not in one's head, but in the performance, and in dyadic interactions with others. ${ }^{11}$ Just as we become who we are in our everyday situated interactions with others, in the acting performance one becomes the character who is elicited by the other characters and by the staged situation. According to this interpretation of Meisner's technique, empathy is not a tool to be used by the actor; it is something enacted in the acting performance, not unlike Ryle's child who in pretend playacts the bear.

We note that these different approaches to acting are prescriptive ones. They specify how, ideally, the actor ought to act and how empathy fits that prescription. Our own interest, in contrast, is descriptive. We are asking how empathy works in the various possibilities that acting allows. In this respect there may not be one clear-cut answer since those possibilities may vary depending on which technique or method the actor uses.

\section{A Twofold Conception}

To give us a sense of how empathy works in the various possibilities that acting allows, we propose to adapt the notion of "twofoldness" that Wollheim (1987) uses to characterize a double aspect of depiction in art. For Wollheim, our experience of a work of art is twofold in that it has a double intentionality: ${ }^{12}$ it is a co-consciousness (or what phenomenologists sometimes call an 'apperception') of what is represented and of the work of art as a thing involving or expressing a technique of representation. Wollheim thus emphasizes a kind of double intentionality in which we know that we are not face-to-face with the painted (represented) figure, yet we encounter or see-in the painting the character portrayed. Importantly, he emphasizes, these are "two aspects of a single experience that I have ... two aspects [that are] distinguishable but also inseparable... [T] hey are not two experiences" (1987, p. 46).

\footnotetext{
11 In this regard there may be significant differences in empathic performance between acting on stage with other actors and acting on camera where it is often the case that an actor is not in face-to-face contact with her interlocutor. In this case the director, but especially the script and the actor's N-imagination may be even more crucial for empathic performance. In stage production practices of blocking (which include the design of the performance space, the placing and movement of objects or props, and especially the positioning of actors for a particular scene helps to scaffold the actor's performance; in film, however, according to the film actor Richard Gere (in conversation), good writing (i.e., a good screenplay) can do something similar.

12 We take the term 'double intentionality' from Scruton (2009) who makes a similar point in the context of music.
}

Smith (2011, $279 \mathrm{ff})$ uses Wollheim's notion of twofoldness to characterize the relation between the audience and the character/actor. In both of these analyses the phenomenon of twofoldness, the ability to "see-in" the physical aspects of the artwork, or the craft of the actor, the object depicted or the character portrayed, concerns the observer or audience perspective on the work of art or the character. To see how this may be applied in the context of acting, consider Jean-Paul Sartre's example of the French actress Claire Franconay impersonating Maurice Chevalier (Sartre 2004, 25 ff). As a member of the audience watching Franconay, according to Sartre, one is always aware that one is witnessing an impersonation; when one imagines Chevalier with the help of Franconay, one is always aware that Chevalier is not literally present, but imagined. There is a kind of double consciousness that on the one hand allows you to see Chevalier, and on the other hand allows you to critically ask whether Franconay is getting it "right." In his analysis of this consciousness Sartre indicates two important features: that there is a knowledge (a prior knowledge of Chevalier and the characteristic things that he would do on stage, as well as the knowledge that Chevalier is not present), and an affective aspect-("All perception [i.e., of Franconay] is accompanied by an affective reaction" [2004, p. 28])—a feeling of the presence of Chevalier.

The notion of twofoldness has also been explained within the framework of simulation theory. Part of the simulationist story as it applies to the observer/audience perspective is that basic mirror system processes activated when we see the character portrayed may also be activated in response to noticing the actor's portrayal, including details of her technique. This is an argument made by Joerg Fingerhut (2018), drawing from both Smith $(2011,2017)$ and the theory of Freedberg and Gallese (2007). Again, this is a theory drawn from an analysis of what happens in viewing an artwork (e.g., a painting or sculpture) and applied to what happens when we are part of the theatrical audience. With respect to the artwork, Freedberg and Gallese argue that various physical properties of artwork allow the observer to grasp the artist's style by activating the mirror neuron system (MNS), which responds to the physical aspects in the artifact even if no human figure is represented (Umiltà et al. 2012). Fingerhut summarizes more recent research.

In a recent series of studies, Heimann, Gallese, and colleagues have applied MNS paradigms also to the study of filmic means. They used different edits (continuity vs. noncontinuity editing) or different camera and lens movements (zoom vs. dolly cam vs. steady cam) to film the same scene. As they discovered, those different configurational aspects of the presentation of a scene engage the motor system [of an audience member] differentially (see Heimann et al. 2017, for cuts, 
and, 2014, for camera). In each of their self-produced scenes there is an actress/actor present, grasping or passing an object. (Fingerhut 2018, p. 32).

On this simulationist view the MNS is seemingly affected in a double way, attuned to both the character (or the action) being portrayed and the editorial and filmic techniques that shape the scene's meaning. Details that pertain to context and are shaped by the camera and filmic techniques are shown to affect subpersonal processes that inform our perception. Such filmic techniques may be something we become conscious of from a critical perspective, in the same way that, as Sartre suggests, we may become conscious of how well Franconay is doing Chevalier. Picking up on this Sartrean point, since an actor is present and engaged in some action in the experimental film, the viewer may be attuned to the actor's technique as well as to the action portrayed. This kind of diplopia may involve shifting from one focus to another, sometimes being absorbed in the character and story line, and sometimes noticing the filmic or acting techniques. But as Wollheim suggests, this may also be one double experience.

We suggest that this same kind of twofoldness or double attunement also applies, with some modification, ${ }^{13}$ from the perspective of the actor who must, at certain points of preparation, distinguish between the character portrayed and her own portrayal effected in her craft. This double attunement is not the same thing as empathy but both basic and higher-order empathy can help fine-tune this twofoldness in the actor. Indeed, in her performance the basic empathic experience that emerges is correlated to an integrated set of subpersonal (motoric, kinaesthetic, affective) processes since in the performance the character's actions are in fact generated by the actor's own movements of which she is prereflectively aware. At the same time the actor's higher-order empathic understanding of the character needs to be folded into this embodied-affective performance. Her higher-order empathic understanding of the character operates as a guide to her awareness of her own technique and about whether

\footnotetext{
13 There are important complications involved in applying this idea to the actor rather than the audience. As one reviewer suggested, the audience member empathizes with the portrayed character on stage whereas the actor who performs the role is somehow on both sides of the empathic relation, being both the empathizer and performing the character with whom she is empathizing. That this kind of ambiguous "reversible" relation is not only possible but familiar in everyday life is made clear by phenomenologists like Merleau-Ponty (2012) in his description of our relation to our own body which is both the body that experiences (lived body or Leib) and the body that we can experience as an object (Körper). This ambiguity, which allows for shifting our perspective on ourselves, is also related to the phenomenological explanation of empathy which, as noted above, involves the (ap) perception (or co-perception) of the other person's lived body grasped through the experience of our own lived body.
}

she is getting the character "right." The double attunement happens when this higher-order empathic attitude is embedded in and is codetermined by the basic empathic attitude, so that both attitudes are present in a figure-ground relation.

This double attunement, which in some instances may involve a shifting from background to foreground, from one perspective to another is, for the actor, a shift from an inperformance awareness of the world and others through the eyes of the character, to a self-awareness of performance. ${ }^{14}$ This is a kind of expert ability that involves maintaining and at the same time manipulating what we characterized (in Sect. 2) as integrated processes of basic and higher-order empathy that are not always clearly distinguishable off stage, in everyday life. This kind of dynamical shifting from background to foreground and vice versa may be more sustained or frequent as the actor prepares her role. It becomes less frequent, and closer to a fully integrated experience during performance. Accomplishing this double attunement takes rehearsal and work which are transformed into performance. These processes constitute the actor's expertise. From the perspective of the actor, self (i.e., the actor) and other (the character) are still distinguishable, but also inseparable in the performance. It is the twofoldness of the experience that prevents us from conceiving of the actor-character relation as one of identity, which would destroy the empathic relation.

In everyday life, instances of empathy that may be initiated in our basic responses to others involving embodied (motor, kinaesthetic, perceptual and affective) processes can progress into higher-order concerns about understanding context (via $\mathrm{N}$-imagination). In contrast, for the actor who must study and prepare and rehearse her character, the process may begin with higher-order processes that provide a contextualized empathic understanding of the character that eventually and to varying degrees, integrates with the more basic empathic processes in her actual performance.

Acknowledgements SG's research on this paper was supported by the Anneliese Maier Research Award from the Humboldt Foundation, and by an Australian Research Council (ARC) Grant, Minds in Skilled Performance. Grant No. DP170102987.

\section{Compliance with Ethical Standards}

Conflict of interest The authors declares that they have no conflict of interest.

Ethical Approval This article does not contain any studies with human participants or animals performed by any of the authors.

\footnotetext{
14 This may involve an enhanced form of pre-reflective self-awareness similar to that described by dancers, musicians and athletes (see Christensen et al. 2016; Gallagher 2018; Montero 2010; Salice et al. 2017).
} 
Open Access This article is distributed under the terms of the Creative Commons Attribution 4.0 International License (http://creativeco mmons.org/licenses/by/4.0/), which permits unrestricted use, distribution, and reproduction in any medium, provided you give appropriate credit to the original author(s) and the source, provide a link to the Creative Commons license, and indicate if changes were made.

\section{References}

Benedetti J (1998) Stanislavski and the actor. Methuen Drama, London

Brecht B (1975a) A short organum for the theatre. In: Willett J (ed \& trans.), Brecht on theatre: the development of an aesthetic. Methuen., London p 181, § 4

Brecht B (1975b) Alienation effects in chinese acting. In: Willett J (ed \& trans.), Brecht on theatre: the development of an aesthetic. Methuen, London

Christensen W, Sutton J, McIlwain DJ (2016) Cognition in skilled action: meshed control and the varieties of skill experience. Mind Lang 31(1):37-66

Connolly R, Ralley R (2007) The laws of normal organic life or Stanislavski explained: towards a scientific account of the subconscious in Stanislavski's system. Stud Theatre Perform 27(3):237-259

Cook A (2007) Interplay: the method and potential of a cognitive scientific approach to theatre. Theatre J 59(4):579-594

de Vignemont F (2012) What is it like to feel another's pain? Philos Sci 79(2):295-316

Decety J (2005) Une anatomie de l'empathie. Psychiatr Sci Humain 3(11):16-24

Diderot D (1883) The paradox of acting [Le paradoxe sur le comedien] Trans W. H. Pollock. Chatto and Windus, London

Dilthey W (1976) Dilthey: selected writings. Trans. Rickman HP. Cambridge University Press, London

Dilthey W (1992) Gesammelte Schriften. vol 7, Der Aufbau der geschichtlichen Welt in den Geisteswissenschaften. B. G. Teubner Verlagsgesellschaft, Stuttgart

Dilthey W (2002) The formation of the historical world in the human sciences. In: Makkreel R, Rodi F (eds) Selected works, vol 3. Princeton: Princeton University Press, pp 101-174

Du Bos J-B (1748) Critical reflections on poetry, painting, and music, vol 3. Trans. Nugent T, reprinted 1978. AMS Press, New York

Esper W, Dimarco D (2008) The actor's art and craft: William Esper teaches the meisner technique. Anchor Books, New York

Fingerhut J (2018) Embodied seeing-in, empathy, and expansionism. Projections 12(2):28-38. https://doi.org/10.3167/ proj.2018.120205

Foster SL (2005) Choreographing empathy. Topoi 24(1):81-91

Freedberg D, Gallese V (2007) Motion, emotion and empathy in esthetic experience. Trends Cognit Sci 11(5):197-203

Gallagher S (2007) Simulation trouble. Soc Neurosci 2(3-4):353-365

Gallagher S (2008) Neural simulation and social cognition. In: Pineda JA (ed) Mirror neuron systems: the role of mirroring processes in social cognition. Humana Press, Totowa, p 355-371

Gallagher S (2012) Empathy, simulation and narrative. Sci Context 25(3):301-327

Gallagher S (2017) Enactivist interventions: rethinking the mind. Oxford University Press, Oxford

Gallagher S (2018) Mindfulness and mindlessness in performance. Italian J Cognit Sci 5(1):5-18

Gallagher S, Allen M (2018) Active inference, enactivism and the hermeneutics of social cognition. Synthese 195(6):2627-2648

Gallagher S, Hutto D (2008) Understanding others through primary interaction and narrative practice. In: Zlatev J, Racine T, Sinha
C, Itkonen E (eds) The shared mind: perspectives on intersubjectivity. John Benjamins, Amsterdam, pp 17-38

Gallagher S, Hutto D (2019) Narrative in embodied therapeutic practice: getting the story straight. In: Payne H, Tantia J, Koch S, Fuchs T (eds) Embodied perspectives in psychotherapy. Routledge, London

Gallese V (2001) The "shared manifold" hypothesis: from mirror neurons to empathy. J Conscious Stud 8:33-50

Gallese V (2008) Mirror neurons and the social nature of language: the neural exploitation hypothesis. Soc Neurosci 3(3-4):317-333

Gazzola V, Keysers C (2008) The observation and execution of actions share motor and somatosensory voxels in all tested subjects: single-subject analyses of unsmoothed fMRI data. Cereb Cortex 19(6):1239-1255

Geiger M (1910) Über das Wesen und die Bedeutung der Einfühlung. In: Schumann F (ed) IV. Kongress für experimentelle Psychologie (29-73). Barth VJA Leipzig 2010/2011. Translated by Gödel F, Aragonaas M (2015) On the essence and meaning of empathy (Parts I \& II). Dialog Philos Mental Neurosci 8(1):19-31 and $8(2): 75-86$

Goldman A (2005) Imitation, mind reading, and simulation. In: Hurley S, Chater N (eds) Perspectives on imitation II. MIT Press, Cambridge, pp 79-93

Goldman A (2006) Simulating minds. Oxford University Press, Oxford

Goldman A (2011) Two routes to empathy. In: Coplan A, Goldie P (eds) Empathy: philosophical and psychological perspectives. Oxford University Press, Oxford, pp 31-44

Goldstein K, Scheerer M (1964) Abstract and concrete behavior: an experimental study with special tests. Evanston, IL: Northwestern University. Reprint of Psychological Monographs 53(2):1941

Goldstein TR, Winner E (2010) A new lens on the development of social cognition: the study of acting. In: Milbrath C, Lightfoot C (eds) Art and human. Taylor \& Francis Group, New York, pp 221-247

Grodal T, Kramer M (2010) Empathy, film, and the brain. Recherches sémiotiques/Semiotic Inquiry 30(1-2-3):19-35

Hatfield E, Rapson RL, Le YCL (2011) Emotional contagion and empathy. In: Batson CD et al (eds) The social neuroscience of empathy. MIT Press, Cambridge, pp 19-30

Hauk O, Johnsrude I, Pulvermüller F (2004) Somatotopic representation of action words in human motor and premotor cortex. Neuron 41(2):301-307

Heimann K, Umiltà MA, Guerra M, Gallese V (2014) Moving mirrors: a high-density EEG study investigating the effect of camera movements on motor cortex activation during action observation. J Cognit Neurosci 26(9):2087-2101

Heimann K, Uithol S, Calbi M, Umiltà MA, Guerra M, Gallese V (2017) 'Cuts in action': a high-density EEG study investigating the neural correlates of different editing techniques in film. Cognit Sci 41(6): 1555-1588

Husserl E (1952) Ideen zu einer reinen Phänomenologie und phänomenologischen Philosophie. Zweites Buch. Phänomenologische Untersuchungen zur Konstitution, Husserliana 4. Martinus Nijhoff, Den Haag

Husserl E (1964) Cartesian meditations. Trans. D. Cairns. Kluwer Academic, London

Husserl E (1973) Zur Phänomenologie der Intersubjektivität I. Husserliana 13. Martinus Nijhoff, Den Haag

Husserl E (1980) Phantasie, Bildbewusstsein, Erinnerung (Husserliana XXIII). Martinus Nijhoff, Den Haag

Hutto DD (2007) The narrative practice hypothesis: origins and applications of folk psychology. R Inst Philos Suppl 60:43-68

Jacob P (2011) The direct perception model of empathy: a critique. Rev Philos Psychol 2(3):519-540

Kaltwasser L (2018) Sharing the filmic experience-the physiology of socio-emotional processes in the cinema. In: Conference 
presentation: being moved. art, film, narrative, and the body-brain (June 4-6 2018) Berlin

Kosslyn SM, Thompson WL (2003) When is early visual cortex activated during visual mental imagery? Psychol Bull 129(5):723

Lamy B (1699) La Rhétorique ou l'art de parler, 4th edn. n.p, Amsterdam

Lipps T (1905) Die ethischen Grundfragen. Leopold Voss Verlag, Hamburg

Lipps T (1906) Ästhetik. Verlag von L. Voss, Leipzig

Lipps T (1909) Leitfaden der Psychologie. Engelmann, Leipzig

Lutterbie J (2011) Toward a general theory of acting: cognitive science and performance. Springer, Berlin

Merleau-Ponty M (2012) Phenomenology of perception, Trans Landes D. Routledge, London

Metcalf JT (1931) Empathy and the actor's emotion. J Soc Psychol 2(2):235-238

Montero B (2010) Does bodily awareness interfere with highly skilled movement? Inquiry 53(2):105-122

Moran D (2017) Intercorporeality and intersubjectivity: a phenomenological exploration of embodiment. In: Durt C, Fuchs T, Tewes $\mathrm{C}$ (eds) Embodiment, enaction and culture: investigating the constitution of the shared world. MIT Press, Cambridge, pp 25-46

Nelson K (2003) Narrative and the emergence of a consciousness of self. In: Fireman GD, McVay TEJ, Flanagan O (eds) Narrative and consciousness. Oxford University Press, Oxford, pp 17-36

Price CJ, Devlin JT (2011) The interactive account of ventral occipitotemporal contributions to reading. Trends Cognit Sci 15(6):246-253

Raz G, Winetraub Y, Jacob J, Kinreich S, Maron-Katz A, Shaham G, Podlipsky I, Gilam G, Soreq E, Hendler T (2012) Portraying emotions at their unfolding: a multilayered approach for probing dynamics of neural networks. NeuroImage 60:1448-1461

Richner ES, Nicolopoulou A (2001) The narrative construction of differing conceptions of the person in the development of young children's social understanding. Early Edu Dev 12:393-432

Ricoeur P (1992) Oneself as another. Trans. K. Blamey. University of Chicago Press, Chicago

Rucinska Z (2014) Basic pretending as sensorimotor engagement. Contemp Sensorimotor Theory 15:175-187

Ryle G (1949) The concept of mind. Hutchinson, London

Salice A, Høffding S, Gallagher S (2017) Putting plural self-awareness into practice: the phenomenology of expert musicianship. Topoi. https://doi.org/10.1007/s11245-017-9451-2

Sartre J-P (2004) The Imaginary, trans. J. Webber. Routledge, London

Schleiermacher F (1977) Hermeneutics: the handwritten manuscripts. Trans. Duke J, Forstmann J. Scholars Press, Missoula [Original: Compendium, 1819]
Scruton R (2009) Working towards art. Br J Aesthet 49(4):317-325

Shuler MG, Bear MF (2006) Reward timing in the primary visual cortex. Science 311(5767):1606-1609

Singer T, Seymour S, O'doherty JP, Stephan EK, Dolan RJ, Frith CD (2006) Empathic neural responses are modulated by the perceived fairness of others. Nature 439:466-469

Slovic P (2007) If I look at the mass I will never act: psychic numbing and genocide. Judgm Decis Mak 2:79-95

Smith M (1995) Engaging characters: fiction, emotion, and the cinema. Clarendon Press, Oxford

Smith M (2011) On the twofoldness of character. New Lit Hist 42(2):277-294

Smith M (2017) Film, art, and the third culture: a naturalized aesthetics of film. Oxford University Press, Oxford

Stanislavski C (1936) An actor prepares. Trans. E. R. Hapgood. Theatre Arts Inc., New York, reprinted 1989, Routledge, London

Stein E (2012) On the problem of empathy. Trans. W. Stein. Springer, Dordrecht

Stueber KR (2006) Rediscovering empathy: agency, folk-psychology and the human sciences. MIT Press, Cambridge

Stueber KR (2008) Reasons, generalizations, empathy, and narratives: the epistemic structure of action explanation. History Theory 47:31-43

Tettamanti M, Buccino G, Saccuman MC, Gallese V, Danna M, Scifo P et al (2005) Listening to action-related sentences activates frontoparietal motor circuits. J Cogn Neurosci 17:273-281

Thompson E (2001) Empathy and consciousness. J Consci Stud $8(5-6): 1-32$

Titchener EB (1909) Lectures on the experimental psychology of thought-processes. Macmillan, New York

Umiltà MA, Berchio C, Sestito M, Freedberg D, Gallese V (2012) Abstract art and cortical motor activation: an EEG study. Front Hum Neurosci. https://doi.org/10.3389/fnhum.2012.00311

Wollheim R (1987) Painting as an art. Thames and Hudson, London

Xu X, Zuo X, Wang X, Han S (2009) Do you feel my pain? Racial group membership modulates empathic neural responses. J Neurosci 29(26):8525-8529

Zahavi D (2001) Beyond empathy: phenomenological approaches to intersubjectivity. J Conscious Stud 8(5-7):151-167

Zahavi D (2012) Empathy and mirroring: Husserl and Gallese. In: Breeur R, Melle U (eds) Life, subjectivity \& art. Springer, Dordrecht, pp 217-254

Zahavi D (2014) Self and other: exploring subjectivity, empathy, and shame. Oxford University Press, Oxford 